\title{
Foul Play in Sport as a Phenomenon Inconsistent with the Rules, yet Acceptable and Desirable: Ethical Conditions
}

\author{
Jerzy Kosiewicz
}

Josef Pilsudski University of Physical Education in Warsaw, Poland

KEYWORDS sport, foul play, causes of foul play, theatralization of foul play, game regulations

\section{Introduction}

The main objective of the paper is to point out that although fouls and fouling in sports are prohibited by regulations of particular disciplines, and despite the threat of more or less strict penalization for such behavior, fouls and fouling are commonly and frequently used by competitors (the scope and motivation for their performers doesn't change). Fouls and fouling are stimulated by the particular society connected to the sport and competitors.

Neither rules and regulations nor prohibitions and injunctions having a practical and praxeological (assuming efficacy) character are able to eliminate fouls, fouling, and foul play ${ }^{1}$. Moral penalization doesn't

\footnotetext{
${ }^{1}$ Three expressions play an important cognitive function in the paper: fouls, fouling, and foul play. They require at least shortened clarification. They refer in this paper to sporting events and other events related to sports. Each of these
} 
help either. In sports, moral types of penalization have, at best, secondary importance. The rules of game are treated instrumentally, rather than as autotelic. No one takes the rules of game as inspiration for moral behavior or as a challenge to behave morally. The rules are not a measure of universal and necessary ethical obligation (the basis for the formulation of necessary and universal moral norms).

Morality (or in this case, moral standards) is, in fact, external to sport: it is not internally, that is essentially and inherently, tied to sport. Morality does not penetrate the structure and content of sport; it is not essentially meshed with sport, because the essence of each sport is solely designated by its regulations and rules. Skills - that is, technical and tactical training - and the entire sports infrastructure, including the buildings and architectural space, the necessary equipment, accessories and players' apparel, are adapted to the statutory objectives.

Since the rules of games and competition, as well as the various administrative sports associations (legalized in the court registers), are not effective and do not produce restrictive results relating to the reduction of fouls, the greatly relativized moral standards, including the variously understood fair play, do not subsequently prevent and will not prevent the occurrence of fouls ${ }^{2}$. This is due to the fact that there is vital demand with various motivations for fouls, fouling, and foul play existing in the community of people who are interested in sport.

This demand is manifested not only in the form of tacit acceptance, but is also manifest in many situations when a foul is carefully planned and desirable.

The demand, need, acceptance, desire, and tolerance for fouls, fouling and foul play relate primarily to athletes, their teams, their coaches, owners of particular clubs, fans, and other people or institutions connected with the teams. On the other hand, players affected by a foul, and the community associated with them, take, in this case, the opposite position: they demand exemplary punishment of the rivals performing the foul(s).

concepts can be presented or defined in general terms, as they relate to many popular and lesser-known sports disciplines. The particular types and the most typical cases of fouls, fouling, and foul play have been characterized in this paper. Thus, the paper provides the most characteristic phenomena of the aforementioned expressions.

A foul is a concept referring to the phenomenon of a deliberate or accidental violation of rules of the game, the regulations, and provisions of the competition associated with a particular sports discipline and the competition on a local, national, international, continental, or global level. Examples are the Olympic or club level competitions. A foul leads to a distortion of the current course of a game; interrupts physical effort; impedes psychological motivation and concentration; and deranges the technical and tactical assumptions of game. It causes the opponent to be unable to continue competing in the previously developed form.

The concept of fouling refers to the deliberate or accidental actions appearing in the game, which conflict with its provisions (rules, regulations). In the first case, that is, in deliberate fouling, intentional actions are conducted, such as harmful and illegal catches (the player grabbing an opposing team's player T-shirt to prevent him from carrying out a successful attack), or disabling, powerful punches (for example, by water polo players under water)or kicks. In the latter case, we are dealing with accidental fouling, resulting, for example, from an incorrectly applied technical element (for instance, the result of an incorrectly applied slide tackle in soccer when the player wants to stop the opponent but instead of striking the ball, the player undercut the opponent's legs).

Foul play can be understood in at least three ways:

- In the first approach the concept of foul play is understood as a game (in this case, a sports rivalry), during which there are fouls in which players foul their opponents.

- The second understanding is the deliberate use of a foul against the opponent in order to use its effects to improve one's own situation in the pursuit of sports success. This is a tactical foul play. This paper discusses it in more detail.

- In the third approach foul play is regarded as a manifestation of a "game" within the game. It involves a player playing a game and pretending to be the victim of a foul, or imitating being injured during the clash in which the rules of game are being broken. In such cases we can call this theatricalization or dramatization of behavior during the competition (sports game).

${ }^{2}$ Six major approaches towards the interpretation on the meaning of fair play might be distinguished. Among them there are views claiming that the rules of fair play are an anachronistic and quixotic phenomenon in contemporary sport; that the values of fair play are external in relation to the sport, even though they are considered to be important; and that sport takes place beyond moral good and evil (Kosiewicz, 2011). 
A afore mentioned demand, need, acceptance, desire and tolerance for fouls, fouling, and foul play neutralize or destroy values and autotelic attitudes. This invalidates the need for recognition, interiorization, and acceptance of normative ethics in sport, including the idea of fair play. A strictly pragmatic and praxeological point of view exists: the balance of costs and profits, the potential benefit, and the advantage(s) accompanying a competition's final results dictates what is accepted and desired in sport. In order to achieve success in sports, the regulations of specific disciplines are also used. It is neither compliance with the standards of pure play (that is, strict application of the provisions) nor adherence to the rules of fair play that are of any importance when the only thing that matters is the final, concrete result of the competition.

\section{Game regulations and fouls}

When considering the occurrence of fouls, fouling, and foul play in sport, a variety of forms of fouls can be distinguished, regardless of whether one is considering direct or indirect competition. This is the same for the phenomena of any other form of aggression. One can thus distinguish fouls that affect the body, psyche, and relationships. In the latter case, fouls impact social conditioning, social involvement, and the determinants of those involved with particular forms of athletic activity. When categorizing fouls, we can also distinguish the fouls committed on the field from fouls committed off the field, including those fouls not even related to a particular game. Our considerations include fouls of a verbal or auditory nature; fouls in the form of printed material; and fouls in the form of appearances in film, TV, or the Internet. This can include feature films and dramatized documentaries. These fouls can also occur in reports presented in various publications, festivals, and exhibitions in which participants, adversaries, or competitors make comments about past or future events. Such events might have happened during a competition or beyond the confines of a competition.

Fouls will always stand in conflict with other forms of aggression or violence, which some sport disciplines not only justify through their rules but also support and encourage as a statutory element for those disciplines. These other forms of aggression and violence are elements that are required, intrinsic, coherent, instrumental, and task-oriented for these particular disciplines (Kosiewicz, 2010a ; Parry, 2002).

Fouls in sport, particularly those committed by athletes during competition, will never be in accord with the accepted rules of the game, i.e., with the official regulations. Fouls will also always influence - in annoying, depressing, harmful, or sometimes even tragic ways - the fate and health of athletes. When only taking into account the rules of the game and the legislative intent explicitly expressed (included) in regulations, fouls in sport are negative phenomena. They are therefore not necessary, coherent, or recommended in sport. There is no logical relationship, i.e., cause and effect-based relationship, between a foul and the regulations governing a particular sport discipline. Neither the need for nor praise of foul play stems from the rules. To be more precise: this means that a description of the pragmatic (that is, practical) rules of conduct in particular disciplines, which are similar in their regulatory overtone to legal provisions, do not logically (that is, according to the logical procedure employed by David Hume in his analysis of the concept of naturalistic fallacy (Hume, 1947, and 1963; Jedynak, 1974) indicate, that foul play might or ought to appear in sports ${ }^{3}$. This cannot be logically derived from regulations or their description that the major or

\footnotetext{
${ }^{3}$ In the sentence referring to D. Hume, I would like to point out (this footnote is to clarify my point of view) that in taking into account the concept of the naturalistic fallacy of the Scottish philosopher, it may be said that the regulation of particular sports disciplines and the descriptions of pragmatic and praxeological rules of behavior in sport (which are similar in their regulative scope to legal provisions) does not logically imply, for two reasons, that fouling might or should be used.

Firstly, more or less detailed regulations or rules of particular sports disciplines are also its most representative, competently comprehensive and summarized definition. It is a summarized definition because almost all its threads/aspects can be extended or be made more specific, more detailed, and relevant examples can be provided to justify the adopted provisions. It is a comprehensive definition in the sense that the provided information is sufficient to determine the rules of the competition related to that discipline. It implicitly or explicitly refers to the existing or potential - that is, those that are still to come - technical and tactical solutions or the infrastructure, equipment, supplies, or sports clothing. This type of definition is also the description of the properties of the particular sports discipline; it
} 
contains explanations connected with it and allows people to understand it. The definition also contains specific postulates in the form of instrumental values of strictly utilitarian properties. The regulations do not contain any guidance of moral overtone. If, however, the regulations contained such moral guidance,they would not have ethical properties (in the sense of normative ethics), but would rather have praxeological character, conditioning the proper, effective and efficient course of sport competition, that is, an efficient action characterized by Tadeusz Kotarbiński in Praxiology: An introduction to the science of efficient action (1982).

Secondly, Hume argued that from a "pure" and devoid-of-value description of nature and the description of human being characteristics any "oughts" or other stimulants of human behavior cannot be and are not derived. In his opinion, the standards of moral conduct cannot, and are not, derived from any objective description (for example, the description of the value contained in the descriptive sociology of morality) that is devoid of values. Another question is whether the description indicated by Hume is impossible to be composed. This subject was considered by M. Black (1964), R. M. Hare (1964), D. Z. Philips (1965), J. S. Searle (1976), P. T. Geach (1977), J. Hołówka (1981), and J. Kosiewicz (1989).

The purpose for this consideration is to show that the moral postulates - moral oughts - don't stem from the rules or regulations of a particular sports discipline (regulations are understood as the ideogenetic, nomothetic and praxeological definition of sport discipline intended to facilitate the understanding of particular physical activity). Therefore, ethical standards are external to the sporting regulations. While they may impact the athletic competition, they are not the source and the internal component of competition; they are not the essence and the meaning of competition. Taking this point into consideration, it might be stated - in my opinion - that the premises of sport are beyond moral good and evil. To interfere with the conduct of competitive sport with morality means to try to change the source identity of sport competition (Kosiewicz, 2010).

From this point of view, the content and a spirational tone of the category of gamesmanship loses its importance somewhat. The category refers to use of ethically dubious means to achieve success (for instance, the victory) but without formally breaking the rules of the competition. This concept focuses on the moral valuation, on the ethical attitudes, on the attempt to determine what in the sport - that is, in the behavior of players - is morally good or evil. This raises significant concerns, because moral standards (not only in my opinion) have no objective or universal criteria or other - fixed and unchanging - points of reference; they have no common denominator: in formal terms (they are situated outside the true and false in the logical sense), methodological terms, and axiological terms. They have relative, relational, subjective, occasional, or situational character. This is due to the fact that they depend on geographical, historical, civilizational, cultural, political, economic, national, ethnic, racial, religious, or ideological conditions.

However, it is possible to assume that the relativity of moral good and evil does not apply to Socrates's view. For him the virtue is absolute (not relative) good. Also, in Plato's philosophy the idea of the good is objective and universal. Immanuel Kant's categorical imperative in his opinion also applies universally and necessarily. Similarly, part of Catholic ethics assumes consistent moral rigor (but not Christian prudence that is close to moral situationism).

Because there is a large number of different and contradictory - from a logical, methodological, and axiological point of view - positions, it is impossible to unequivocally and unquestionably determine what may be morally reprehensible and doubtful. It always depends - not just in my opinion - on the adopted and relative point of view. This is the reason for - as I define it - disorientation, confusion, and moral chaos: chaos in the realm of existing and recommended ethical standards. It can be assumed now that the term "ethical relativism," used in relation to the heated melting pot containing a mixture of moral norms, is an insufficient concept that is too moderate. We are currently experiencing a complete chaos, a lack of compatibility of various and differently justified moral assessments, standards, models, schemes, and codes (that is, moral models). It is legitimate to say that with regard to moral models we are experiencing uncontrollable confusion.

If during the game there is no incident of breaking the rules, as it is indicated by the definition of gamesmanship, then we are dealing with a case of pure play (and not with foul play, fouls, and fouling), which is a phenomenon expected and also worthy of approval (from the point of view of a specific definition of sport, which includes the regulation of this game). If this is the case, the assumption or belief that an opponent can be charged with the additional non-objectified and non-commonly accepted moral standards (in a formal sense) by the registration court of the particular country (where the sports club and the related institutions were registered) loses - in my opinion - the sense and perhaps can be even objectionable. This attitude may be exacerbated when the competition will require participants to adhere to the variables rules that are subjective, relative, impermanent, culturally alien to them, and occur beyond the established rules of the game. These norms can be treated as unnecessary and burdensome moral ballast. Normative ethics and related expectations are in fact, in my opinion, external (transcendent or transcendental, depending on the viewpoint) in a logical and sociological sense (in light of the sociology of morality), and in philosophical sense (in terms of moral philosophy) - in relation to the regulation of a specific sport discipline. If the ethical norms' impact on players abiding by the rules of the game is positive, their role, with some reservations, may be approved. But this is not necessary, as they are not the aim in itself. Ethical standards may only have additive, supportive, and instrumental character in sport. Incidentally, if the rules must be necessarily enhanced by ethical standards, it is an indication that the regulations need to be modified to give them a new regulative shape, so they would be optimally - that is, as precisely as possible - adapted to the current and anticipated needs of the praxeological character. 
even minor (whether secondary or related to particular phase of actions) goal or task for participants in a sports competition is, or must be, fouling. Further, it cannot be implied from the regulations or their description that the use of procedures, techniques, and means that enable, facilitate, or lead to fouling are permitted or recommended as a moral possibility, duty, or categorical imperative. In accordance with the standards expressed in the provisions of particular sports disciplines, foul play is neither implicatively nor instrumentally tied to the regulations of sports disciplines. The rules do not encourage players to use foul play; the rules may only predict the occurrence of foul play as undesirable phenomena and determine the form for its penalization.

\section{Fouls, fouling, and foul play as a result of non-statutory activities}

The absence of any formal or statutory validation of foul play - that is, the lack of a source for the use of foul play in a discipline's formal regulations - does not result in the eradication of this kind of play. Thus, why do fouls occur?

1. Foul play might arise from emotional impulses, which are aimed at the opponent and that have injurious intent. Foul play might be the manifestation of a forbidden form of katharsis, a testimony to the overwhelming need to purify negative and stressful tensions. Fouls may also represent an increasing dissatisfaction with the unfavorable course of the competition; thus, it may be an expression of negative emotions such as rage, anger, and aggression against a rival who is the alleged or actual perpetrator of an assumed - and therefore not necessarily real - failure, or who can be perceived as the actual cause of an impending disaster. Anyway, this type of behavior has the character of potentiality in the sense that, although the rules of a particular discipline may or may not anticipate its appearance, foul play may, but does not have to, appear.

The behavior of an outstanding heavyweight boxer, Andrzej Gołota, could serve as an example. Gołota, annoyed by his opponent's resistance in the fight for the top position in the ranking of candidates (challengers) to fight for the title of world champion in professional boxing, repeatedly struck below his opponent's belt. Gołota was therefore disqualified.

Boxer Mike Tyson, in turn, was disqualified for biting off a piece of Evander Holyfield's ear. Tyson's behavior was the result of negative emotional experiences and showed dissatisfaction with the course of the competition. Holyfield not only successfully resisted, but even began to prevail over Tyson in the match for the world championship.

2. The provisions of a competition may contain implicit suggestions regarding what can be done to achieve the assumed goal beyond the accepted and recommended (in conformity with applicable regulations) tactical and technical solutions particular to a given sports discipline. In fact, the goal might be of major or minor importance; the goal may only relate to a stage within a contest or the goal could be for the entire competition itself; the goal may be for one or several competitions; and the goal may be either temporary or final.

An example of such a case is common in the disqualification that occurs in ski jumping due to a candidate's unauthorized clothing. Even though the rules clearly define the parameters of a ski outfit,

The occurrence of fouls, fouling, and foul play during games indicates that the rules of competition are breached. On the other hand, the concept of gamesmanship, which describes behavior that is consistent with the game's regulations but at the same time morally reprehensible from some point of view, suggests an association of two valuating assumptions that do not correspond with each other. This lack of compatibility stems from ambiguous and autotelic moral standards as well as from praxeological standards of an instrumental character, adopted and considered from the point of view of their effectiveness and efficiency. The violation of the latter - as opposed to the first - may be subject to objective penalization when taking into consideration the codified rules of the game or (if the need arises, and the justification relevant to it) the administrative code, the civil code, and the code of criminal procedure in force in certain countries in which the rules and the law had been breached. This concerns, for example, the banned doping in Italy and the United States. Moral penalization has, on the other hand, no universal character: it is always -I think relational and non-objective. 
individual skiers and their managers are constantly trying to improve the clothing's surface to extend the flight of a jumper. The skiers and their managers interpret the restrictions contained in the rules of this sport - contrary to the will of the rules' creators - such that a transgression of the rules can help skiers achieve better results.

3. According to those involved in a particular sport, the rules of a competition might create a corset that restricts creativity. Further, such rules may too harshly and too oppressively hamper the progress, approach, and eventual achievement of the pursued objectives. To act against the rules is to manifest a desire for freedom and for liberation from imposed and sometimes irrational constraints. These actions can contribute to adjustments to regulations: to the tightening or easing of rules occurring in the regulations. Also, these actions might lead to the incorporation of changes of a nature too difficult to predict.

An example may be taken from volleyball. In the past, individual players attempted to hit the ball twice: first after the failed blocking of the opponent attack; after that, when the ball landed on their side, they try to hit it with a hand or foot. It was then a clear breach of the competition's rules. Currently, though, this kind of play is allowed. It increases the attractiveness and the flow of the game.

\section{A planned foul play}

A foul may be either accidental or carefully planned. In either case, it surprises all when it happens randomly or accidentally; it only surprises some of the competition's participants, players, coaches, and observers when it is formerly planned.

1. The planned foul play can, from the standpoint of efficiency and effectiveness, be skillfully and sensibly woven into the structure of a game and used as a tactical or strategic option (Simon, 2007). Warren P. Fraleigh calls this kind of foul an "intentional tactical rules violation" (Fraleigh 2007, 212213). Li-Hong (Leo) Hsu defines it after Fraleigh as a "good foul" or a "professional foul" (Li-Hong, 2005, 6-7). Foul play in the indicated cases alters the spatial and tactical texture of the game, evoking unexpected emotions and curiosity caused by unanticipated changes in the situation. In examining foul play from a structural and formal position - and putting aside the tragic consequences that may occur, for example, to one's health - it could be conceived that this phenomena might have positive and beneficial implications.

Two examples can be seen. The first indicates that foul play greatly increases the attractiveness and spectacular aspects of professional ice hockey games. A professional hockey team sometimes has one player who specializes in one kind of play: he skillfully and intentionally initiates fights with other players on the ice. He fights effectively. This type of behavior is desirable, although it exposes the hockey player and his team to a variety of penalties.

The second example shows that foul play can bring other and expected beneficial results. This applies to the player a football (soccer) field, who in aiming to score a goal, is fouled just outside the penalty area. This type of foul play - also called the "intentional tactical rules violation" - leads to a free kick outside the penalty area. It does not often result in a goal. For the defending team the benefits of the tactical foul are obvious: it moves the ball away and reduces the threat of giving up a goal. This type of foul not only meets with tacit approval, but is also tolerated and accepted and even desired by fans of the defending team. The opponents - players, coaches, fans, and journalists -condemn this type of behavior and demand its proper penalization.

2. A foul may originate from a player's desire to achieve pleasure that arises from the foul. This applies to a situation when the player is satisfied with the successfully executed application of a deliberate (not accidental) technical foul that results in interrupting a game's running time and is harmful to the opponent (and his team) who was fouled. The foul is also disadvantageous in terms of the fouled player's assumptions regarding the process of the competition. Paradoxically, when taking into account the perpetrator's motivation, this type of foul play may have an autotelic, and not 
instrumental, nature. The foul becomes for the perpetrator the goal itself; it does not serve as a means for achieving pragmatic or utilitarian objectives. Therefore, it is the pursuit and fulfillment of the expectation of good fun. Some fans consider foul play to be an example of a certain type of pure fun. Though this type of good fun happens at someone else's expense, fouling - regardless of autotelic motives - is also the negation of the rules governing a given discipline.

3. An example of this kind foul play is the figure of Leszek Drogosz, the famous boxer who fought in the light weight, light welterweight, and middleweight categories. Drogosz was multiple-time Polish champion (in the 1950s and 1960s; he won his last title in 1970); he was also a multiple-time European champion. His technical and tactical skills were superb. His specialty was foul play in fights against opponents in ways referees could not perceive. Fans raved about his skills. He achieved great popularity. However, the consequences of such behavior can be threefold:

a) Experience of pleasure and an egoistic sense of fulfillment of the player's own selfish needs;

b) Exposure of the victim of the foul to psychological, physical, and relational discomfort; the same danger of exposure relates to the team that is associated with the completion of the victim's sports-related objectives;

c) Exposure of the perpetrator of the foul and his team to penalization; to random loss of opportunities on the way to planned victory, a loss that is not associated with the tactical assumptions of the game.

\section{Foul play and transparency of motives: manipulating the referee's reaction}

When considering the aforementioned reasons for fouls in terms of transparency of intention or motives, we deal with two kinds of foul play.

1. The first type is characterized by deliberate fraud, a planned hoax; a foul in which the real intentions are not available to the referee. Foul play in this case is a manifestation of a sort of "game" within a game that is based on the intentional misleading of a referee. This type of game will be the subject of another paragraph later in this paper.

2. In the second type of foul, we are dealing with open, transparent, and conscious foul play. The nature of this second type of foul is obvious with regards to the benefits that the player will gain when the foul is noticed and, according to the rules of the game, punished. The intention of the player and his team in the second case is for "the game" within the game to be noticed and identified as such. Applied by the referee, punishment might bring both the player and his team essential advantage in the final balance of benefit and loss. Such a possibility occurs, for example, in some situations in basketball, which we will present in more detail further in the paper.

Regardless of the situation, we are dealing in both cases with the manipulation of a referee's behavior. The objective of the manipulation is to force the referee to behave and act in a manner that the player committing the foul assumes and expects. It's worth mentioning that the foul in which the intention of player is disguised (as compared to the foul with transparent and clear intent, the so-called good foul), opens for the referee two possibilities: he can either punish the actual perpetrator of the offense, or he can punish the fouling player's victim. In the first case, the referee does not proceed in accordance with the intention of the manipulator, does not surrender to the fouling player's manipulation, does not follow his suggestion and identify the manipulative character of "the game" within the game. In the second case, the referee complies with the fouling player's suggestions. He acts as the manipulator had assumed.

From the perspective of those who like to consider foul play in light of the principles of fair play, it can therefore be assumed that the obvious foul is a more negative form of behavior than the foul skillfully disguised or masked. The case of a transparent foul might be called "open, obvious or insolent" foul play (Goffman, 1981, 104). However, in both cases, not only are the rules of the game violated (which always 
seems to be a negative quality from the point of view of supporters of fair play), but even worse, the decisions of the referee are manipulated.

\section{Foul play as an accidental phenomenon}

Foul play may also occur as an unintentional mistake in sport that results from series of situations. Among others aspects, foul play could be testimony to:

1. Poor training or preparation for competition. For example, in boxing it is hitting the opponent with an open glove or below the belt;

2. The manifestation of fatigue and loss of a player's necessary physical and mental agility. For example, when physically and mentally exhausted F1 drivers lose control over their cars, and then hit other cars;

3. Mental and physical incapacity caused by an existing illness or one that develops during a game. This includes interrupting competitors' actions in a way that is contraryto regulations: holding; intentionally stepping in front of or undercutting an opponent's leg in football or in handball; illegal clinching in the boxing ring;

4. An improper selection of technical and tactical meansin certain situations. Examples can be found during rugby matches or American football matches: a poorly executed tackle: a defensive attack when a defensive player tries to stop a speeding opponent and throws the opponent to the ground;

5. Improperly prepared sports infrastructure: football field, running track, bicycle racetrack, or horse or car racetrack. In such cases, we can observe stumbles on a running track and collisions on a car or motorcycle track, thus eliminating competitors from competitions;

6. Sports equipment that is poorly prepared, poorly matched, or poorly designed. It could result in collisions in races involving bicycles, motorcycles, or cars;

7. Poor weather conditions: rain, snow, and the slippery playing surfaces that result from poor weather conditions. This is a common cause for collisions during F1 races;

8. Major mental stress caused by the influence of aggressive and demanding attitudes of rivals during the game; the negative impact of mass media, fans, club owner, and trainer; excessive expectations of other team members. Such a situation occurred with international football star Zinedine Zidan. During a football match attached end of his career, Zidan was the victim of an intense aggressive verbal attack from his opponent. He lost his temper and used his head to illegally hit (head-butt) the offending opponent in the chest. He was dismissed from the field.

\section{Fouls, fouling, and foul play and attractiveness of spectacle}

Is a foul able to bring benefits: a) to the practice of competitive sports, and b) to a sports event by increasing its attractiveness? Undoubtedly yes. It is a phenomenon that has become accepted and tolerated but also something that is desirable. The following reasons might assure a positive answer:

The observations stated above in point number three (the paragraphs regarding fouls, fouling and foul play as a result of non-statutory activities) indicate that foul play may (not necessarily directly) result in, inspire, or highlight the need to introduce positive, perhaps even significant, changes that would be especially valuable for competitive sport (Reddiford, 2002). Foul play may in fact contribute to the modification of a competition's regulations or the provisions of a particular discipline. Foul play may also contribute to the exacerbation or mitigation of ensuing fouls and to a significant or less noticeable (but still significant in term of potential damage) reduction of trauma.

With regards to this, two examples can be provided:

The first relates to the evolution of boxing regulations, which has reduced the possibility of fouls by players. The referee's power and ability to penalize competitors has been increased with the power to apply admonitions, warnings, and player disqualifications. 
The second example relates to soccer. For some time now, players (with the permission of trainers) have been trying to ease the game's rules in order to make games more humanitarian by helping the referees execute the field rules. This applies to situations in which a player who was the object of a foul is lying on the field and needs immediate medical attention. Even if the referee does not notice the foul and the unfolding situation, the other team's players would kick the ball out of bounds. Following medical intervention, the injured player's team would pass the ball to their opponents, and they would start the game again.

In response to the second question posed above, foul play might in many ways significantly contribute to changes in the spatio-temporal, spontaneous, or planned structure, blueprint, or scenario of an event and its cognitive and emotional reception. Foul play may contribute to the temporary removal of a competitor or the removal of a greater number of athletes from a competition. This may also result in the temporary or permanent removal from athletic circles, or even in the removal of an athlete from society to the penal system. Foul play not only changes the formal structure of a game and a game's so-called dramatics, but it also - regardless of the legal and moral overtones, that is, withdrawing the multiple axiological and pragmatic contexts as well as the consequences of foul play - brings more attention to the course of events (for example, on the field). It also increases the general interest in the fate of the penalized individuals and teams. The interest can extend to their careers and any transfers or changes in the standings of the individual or team.

For these reasons, fouls, fouling, and foul play are phenomena not only tolerated and accepted, but also desirable, as they increase the attractiveness of sports performance, hence its pageantry and profitability. Financial benefits from advertisers help to strengthen and refine the club and team through the ability to acquire new players and better coaches.

\section{The temptation and the penalty associated with fouls}

Why are athletes tempted to consciously risk disgrace and moral condemnation despite threats of oftonerous penalties, despite an awareness of harm to the health of the individual, and despite the social harm related to the use of foul play? Why do they decide to become subject to the penalties according to the provisions of the competition and, moreover, subject to the potential administrative, civil, and criminal legal procedures?

1. They pursue a willful victory or a tie. In the first case, for example, football players must

"intercept the ball from the rivals, conduct an action, in which they will not allow the opponents to knock them down on the field (in fair or unfair approach) and find themselves in a situation in which they might score a goal" (Janus , 2010, p. 34).

And it has to be at least one goal more than the opponents have scored. On the other hand, for football players to finish a competition in a tie they must at least prevent the opponents from scoring one more goal. In both situations, the player must avoid his opponent's unfair, non-regulatory actions. By playing strongly against rivals, a player can often move a game closer to a more or less distant aim. Often, a player consciously exceeds the game's regulations. Fouling may be the key to success, especially if it impacts the competition's performance or plays a decisive factor in deciding the winner in a championship or in a tournament (Janus, 2010).

2. They take risk because they think that the potential benefits coming from the foul clearly outweigh the possible - but not inevitable - punishment or negative health effects. The benefits can be financial, political, religious, or cultural. Benefits can include fame or even immorality that ensues from the optimum publicity. Usually, foul play is made implicitly acceptable by players and secretly endorsed by the whole environment: in social circumstances, in the changing room, in the coach office, on the field, backstage, and throughout the ethos of sports, the ethos practiced within their profession. In this respect, the final football match of the 2010 World Cup in South Africa can serve as one of many 
examples. The game between Spain and the Netherlands was full of mutually ruthless and harsh fouls. Hockey game brawls are examples as well.

3. This type of behavior enjoys quiet approval; it's even desirable- despite official proclamations otherwise - amongst athletes, coaches, authorities, team owners, and fans.

Beyond doubt, foul play significantly increases a sporting event's attractiveness. This includes:

- Heightening the aleatory nature of a sports event by adding unexpected, unpredictable (for competitors and observers), and random components that occur in both fixed and schematically arranged elements during the event;

- Enriching the dramatic component of a performance as a licentia poetica of its own kind, by saturating it with here-and-now authentic emotion and effort, i.e., with content that is beyond the sport's normal events. Fouls of both kinds - planned and spontaneous - can lead to real personal (and team) tragedy. The hardship might haveovertones related to ambition (due to unfulfilled plans, disappointment over broken hopes for applause and fame, or dreams of winning the championship); related to finance (the elimination of resources for further training and maintenance); related to health; or related to damaged national, ideological, or political relations.

In theatrical plays, events such wars, fights, mutilations, or the aforementioned individual and interpersonal tragedies are not real. They happen as a part of written and scripted sequence of events as seen on stage; they are designed by the playwright, producer, and director. Although previously planned, they have power to elicit sublime aesthetic and artistic experiences, especially in cases of good performances. Viewers of a show experience deep emotions regarding the success or failure of persons involved in the drama on stage.

Dramatic situations that occur during a sports spectacle, such as a permanent injury or even a death due to foul play, happen for real: they are not an isolated metaphysical aesthetic composition suspended in a world of artistic abstraction, separated from the real life by a "fourth wall" or a "magic curtain." They cause deep, varied and authentic experiences. They often result in permanent mental, physical, and relational changes (e.g., family) in athletes, as well as direct and strong emotional excitement among the observers and fans. A positive perception of the whole event (a structural standalone entity) is influenced by one's presence or even better: participation in a most surprising performance, full of dramatic tension, fouls, and unforgettable changes of action. The greater the mass media attention and public opinion the event garners, the longer it will be remembered.

4. The people responsible for the score, the course, and the effectiveness of professional sports competition treat the provisions of particular disciplines both as formalized guides which define the general rules and characteristics, and as general indicators of a competition's limits. The provisions constitute an initial framework, the basis for a road map that contains all the detailed data, that is, the performance's score, in which the primary pragmatic and praxeological goal is to succeed (in whatever way this concept is understood, for example: depending on the situation or relatively understood success).

The main and the most important purpose of competition -in pragmatic, praxeological, and axiological meaning - is not a strict adherence to the rules of the competition, but the optimal use of their content in order to achieve success. The purpose of modern professional sport is not so-called pure play (not to be confused with the fair play), that is, a strict and without exception adherence to the rules of the discipline. The purpose of modern professional sport is to use the rules to achieve another, fully pragmatic (from the standpoint of the final benefit and advantage), praxeological (with regards to effectiveness and efficacy), and strictly egotistical purpose that was assumed in the competition's score. Therefore, people who co-create the plan of the game weigh, on the one hand, the benefits of adherence to the rules, and on the other hand, disobedience in order to achieve both shortand long-term goals (even at the price of severe penalties). 
Therefore, the variety of fouls can be listed. If the foul is planned in advance and appears to be feasible in predictable situations during the game, we are dealing with so-called tactical fouls. The opposite parties accept them, even if such fouls result in painful consequences. These fouls are in fact included in the profit and loss balance of the game. They are a part of the unwritten agreement, a sort of protocol commonly known to particular circles. There they abide, regardless of the possible effects of the actions of judges, commentators, or general public opinion. Analogous is the silent acceptance of the use of various types of doping that occurs in many social and sporting circles. It is accepted among those who remember that for many decades drugs accounted for a significant stimulator in the work of eminent artists and were a part of the ethos of theatristic society.

5. One of the reasons for the increased occurrence of foul play is the widespread commercialization of sport, which is a fetish of contemporary times, the importance of which continuously grows. It rightfully intensifies popular interest in sports, especially sports spectacles. This factor, as well as the increasing expectations of demanding employers who pay huge salaries and bonuses and the expectations of wealthy sponsors hungry for success and ruthlessly enumerating failures, will certainly increase number of fouls. This phenomena will also stimulate the development of fouling, foul play, the effectiveness of fouls, the technical skills of players in achieving them, as well the development of other forms of aggression.

Based on the foregoing considerations, it can be concluded that fouls, fouling, and foul play are phenomena not only tolerated and accepted but also desirable, especially when they increase the attractiveness of sports performance as well as increase the growth of income dramatically and positively. Financial benefits in the form of income from advertisers help to strengthen the infrastructure of sports club and team and help to increase a team's quality through hiring new players and better and increasingly more expensive coaches.

\section{The theatricalization of the foul play - or the "play" element in the game}

The use of foul play is treated by the players, their coaches, employers, and supporters of the team as a constant and essential component of the techniques and tactics of competitive sport. Foul play is a manifestation of a peculiar game; in another words, it is manipulation that aims to mislead a referee. The foul leads to the punishment or even elimination of a competitor, and ultimately weakens the opponent's team. Finally, it results in the defeat of rivals, who like their fans are embittered by a bad verdict. N. van Quanquebecke and S.R. Giessner state that "many fouls committed in football (called soccer in some countries) are ambiguous, and there is no objective way of determining who is the 'true' real perpetrator or who 'true' victim" (2010, p. 3).

This foul play as a "game" appears during a normal game, one consistent with the rules. We then deal with a "game" within a game. The offender "plays" the role of the victim. We are therefore witnessing a game with quasi-theatrical characteristics. The player who performs a foul skillfully simulates, imitates, and applies acting tricks while playing his role of the victim. The "game" within a game contains secret, carefully hidden, and skillfully disguised intentions. In fact, the foul is a psycho- and socio-technical procedure aiming to affect the referee's decision. This is in line with the expectations of the person committing the foul. The referee does not seem to be conscious of the real causes of the situation and the possible consequences of his wrong conduct. Thus, foul play is a deliberate manipulation, a deception misleading the arbitrator (Fraleigh, 2007; Li-Hong ,(Leo) Hsu 2005; Reddiford, 2002; Leaman, 2001); it is unfair conduct that hurts rivals, both the individuals as well as an entire team. The referee is objectified and treated instrumentally as a passive tool used to achieve a goal extraneous to him, contrary to his intentions, which was created by one of the rivals.

From the standpoint of a competitor who performs the foul, the considered "game" is a highly risky task that puts him - when his real intentions are discovered - in danger of incurring the deserved punishment, often stiffer than other penalties, as the foul is judged to be intentional fraud. 
Sociologist Erving Goffman shares this point of view in a book that characterized human life in light of theatrical categories (Goffman, 1981). He claims:

"When we speak of those who mislead and deceive, we think about the discrepancy between the pretence their created and the reality. We also think about how risky is a situation in which at any moment something might happen that the performers of the play will be caught red-handed, at any moment the precipice between reality and the status of things the performers openly presented can be revealed. It brings the jeopardy of humiliation and sometimes a complete loss of reputation" (ibid., p. 101).

Further, Goffman indicates:

"When we discover that someone with whom we deal is a quack or a wriggler, we feel that he had no right to play the role he had played before" (ibid., p.102).

We discover that this person fraudulently benefited from the status that created the illusion of honesty.

The competitor undertakes this quite exciting and thrilling procedure either because he likes such extreme challenges, or because it has been assigned to him by the coach as a necessary - but not statutory technical and tactical operation. Even when intentions are reprehensible, the player's good performance results in a feeling of satisfaction and approval, or even admiration, among members of his team, coaches, and fans. The feeling of disapproval, on the other hand, arises within the injured opponent and people associated with the opponent.

The foul play "game" that occurs during a football match, for example, requires extraordinary skill. It is performed by top athletes, whose conduct and action usually gains popular moral and professional trust, particularly amongst referees and spectators. However, the "game" takes place beyond moral good and evil. It aims to achieve adopted pragmatic advantages: to punish the victim, not the actual offender. The rules are treated as a convention that can be uniquely interpreted and applied as an aid in order to attain a benefit.

Thus, some kind of dramatization, a dramatic act, is happening: one party is pretending to be someone other than actually is. The foundation for such a play is thoroughly and reliably learned behaviors, adjusted to existing situations. The basis for the application of the behavior is relevant practical knowledge (phronesis, Gallagher, 1992; Gallagher, 1993; Dreyfus, 2004) and intuition that indicates at what point and how to play the victim. At the same time the task is to, in extremely skillful ways, blame the actual victim for the result of a situation.

Reference to the theater is not accidental ${ }^{4}$. Although the incidents or situations that happen are certainly not manifestations of any form of theatrical drama, they do comprise highly aleatoric elements of performance, i.e., sports spectacles (Kosiewicz, 2010b). They can be defined as an episode or scene, the existence of which was not previously known. Even when it was assumed that a foul is going to occur, it was

\footnotetext{
${ }^{4}$ Jerzy Szacki, in the Introduction to Erving Goffman's book The Presentation of Self in Everyday Life, in taking his position on the concept that justifies considering human relationships in light of theory and category of theater, states that "theatrical metaphors from everyday speech penetrated sociology; the best example of this is the theory of social roles originated by Ralph Linton and Florian Znaniecki; definitely this theory was also present in the work of Georg Simmel, Charles Cooley, George H. Mead, Robert E. Park and a few others. Ralf Dahrendorf does not exaggerate when he states that '... Shakespeare's metaphor becomes a central principle of a modern science of society.' Park wrote more than half a century ago: 'Everyone always and everywhere, more or less consciously, plays a role [. . .] It is that we know each other and ourselves from the roles that we play.' Where does, then, the growing popularity of Goffman come from? Why does his "dramaturgical approach" become more and more popular, convincing many people that this approach opens a new way, or even a path, in sociology?

I think that at least two major reasons for the growing popularity of the author of The Presentation of Self in Everyday Lifecan be identified. The first reason is the consistency and creativity in using old theatrical metaphor; by those two means the metaphor can be converted into the theoretical scheme, capable of accommodating probably even more than Goffman himself imagined it could include" (Szacki 1981, 7).
} 
not generally known where, in what part of a sports arena, and at what point during a sports spectacle it will occur.

Such an episode can be compared to an event, a spontaneously played situation that had previously been designed. One person provokes an incident involving, supposedly by accident, selected persons such as rivals as well as the referee. The referee, of course, is from a distance tracking the course of the "game" during a game. All the people involved in the situation - the opponent and the referee - have their roles assigned without their own approval. They are involved in staging this pre-planned dramatization regardless of their volitional and emotional attitude towards the event.

The main operator in the situation, the perpetrator of the event, is a director. At the same time, the director plays a major, well planned, and prepared role.

The referee's role can be compared to that of a character from puppet's theater: the puppet. The puppet's behavior is controlled by the director, the most important participant of the event. In a given play, the role of the referee is the worst possible role, since he will be ridiculed if his decision complies with the intention of the director. His is a tragicomic figure, arousing sympathy, as do some characters in the plays of Jean-Baptiste Molière:

- comic, because he does not realize in time that he has been led astray;

- tragic, as in fact he is put to shame, loses his authority, and exposes himself to ridicule, mockery, and laughter.

In turn, a player who is involuntarily hurt plays a tragic role, since he is found guilty, even though he is the real victim of the incident.

The culprit, on the other hand, blows his own trumpet, like a hardboiled crime fiction character. Not only has he escaped justice, but his fraud (his fraudulently used of quasi-imitative acting skills) has been generously rewarded. He played the role of victim so suggestively that the referee trusted him.

This form of foul play, the theatricalization of this phenomenon, can be seen in the perspective of two conflicting approaches. First, from the perspective of the player or team that uses foul play and for the team's manager or owner of the club, foul play is not only tolerated, but even desirable. Second, from the perspective of the disadvantaged player, the team and those more or less closely related to them, this kind of behavior is reprehensible and deplorable.

\section{Sources of referees' misjudgments}

Why can even the most eminent referees, experts of recognized authority with long-standing international practice, be misled?

The causes of their mistakes are primarily rooted in the regulations of particular sports disciplines. The rules require that the perpetrators of a foul will be immediately identified and possibly punished. Therefore, there is no time for in-depth analysis of the event. The time deficit does not allow for consultation with other referees or with any objective observers of the event. No recording devices register the foul play. To play back the video recording would facilitate analysis of the situation.

For example, the referee (main referee) in football makes his decisions based only on his subjective assessment of a given event. It is based literally on one-sided observations on what he saw from one place. While dealing with ad hoc situations, a referee is not allowed to take into account different perspectives of the situation that are available through relevant technology. The event's data are accessible to him from only one perspective, one place.

During boxing matches, at least four judges are present: one referee and three scoring judges. Yet even they make mistakes because they are not able to see everything. Players (not just football players) take this under consideration, and with their skillful "game" dupe judges, deliberately injuring their opponents. 
Quanquebecke and Giessner (2010) noticed that in the case of popular team sports, such as rugby or American football, video recording devices are used. Replayed in slow motion, the recordings take into account a variety of shots and angles of view. The use of these video recordings ought to serve in resolving ambiguous situations. Meanwhile, the Federation Internationale de Football Association (FIFA) presents in this case a different, definitely conservative, position. The federation opposes the application of new technological solutions by referees (FIFA 2007; Warshaw, 2006). In spite of the examples set by rugby and American football, FIFA believes that such instruments only create the technological illusion of objectivity, and might become in fact the cause of other types of errors and distortions during the game.

It is worth mentioning that football referees often rely on data, which they use as quasi-tips when making decisions in complex, ambiguous situations involving contact on the field (Mascerenhas, O'Hare, \& Plessner, 2006). This refers to implicit suggestions contained in psychological research regarding the various causes and conditions of a foul. Among the factors that may affect the decisions of referees in selected situations, the following knowledge can be distinguished: that the "colour of the players uniform" (for instance: black) induces aggressive action towards rivals (Frank \& Gilovich, 1988; Tiryaki, 2005). Also, an important influence on a referee's decisions is the context of "preceding foul judgments" (Plessner \& Betsch, 2001). In their verdicts on an ambiguous situation, referees more or less consciously also take into account opinions about the team and "a team's reputation" (Nevill, Balmer, \& Williams, 2002). The impact a player's height has on behavior, including the use of foul play on the field, was also analyzed. Therefore, the possible application of studies in the field of cognitive psychology is considered, showing an automatic association of tall height with the need to dominate (Quanquebecke \& Giessner, 2010). Greater height gives a sense of strength, power, and physical advantage over rivals (Barsalou, 1999, 2008; Glenberg, 1997; Niedental, Barsalou, Winkielman, Kraut-Gruber, \& Rick, 2005; Lakoff \& Johnson, 1980).

Quanquebecke and Giessner (2010), referring to the aforementioned authors, supposed that during seven-year-long studies focused on football matches in the German Bundesliga, the UEFA Champions League, and the FIFA World Cup, taller players would foul more often than shorter players. It was shown, however, that the taller players were fouled more often. In fact, it was the shorter players who fell down more frequently and then suggested that they had been the victims of a foul.

Nota bene, the additional, aforementioned data concerning the determinants of aggressive behavior and foul play are double-edged, as this knowledge is broadly available, not only to referees but also to players and others associated with professional competition, inter alia, those involved in contact team sports. They can use it skillfully, trying to deceive referees during plays involving fouls.

The codification and application of fouls (with their associated prohibitions and commandments, as well as rules of punishment) must urgently and comprehensively be described, characterized, and constantly updated, as they are an integral part of professional sports. As such, they will always accompany the conduct of competition in a particular discipline of sport as a possible or actual course of action. For the information of all concerned, the formal rules of certain sports should also include descriptions of obvious, noticeable, and potential non-authorized techniques used during competition. Such knowledge should be available not only for those involved in the particular discipline of sport - fans, journalists, and the general public - but also for children and adolescents, and especially parents, in order to acquaint them with the characteristics of risk in professional sports.

\section{Conclusions}

In conclusion: in light of the discussed considerations, fouls, fouling, and foul play is used in sport, although these elements are not a form of competition that comply with rules of particular sports disciplines. Yet people directly associated with sports tolerate, accept, and allow fouls, as there is widespread and quiet acquiescence of such play. Foul play is strongly opposed by supporters of the principle of fair play, by those who do not regard sports competition as a phenomena that can be considered independently beyond moral good and evil (Kosiewicz 2010, pp. 21-29). 
Fouls, fouling, and foul play are also seen as desirable phenomena, when regardless of the various penalties imposed on players and team, it helps - in the final balance of losses and benefits - to achieve the planned success. It is worth adding that the so-called good foul in basketball enables one to stop the game clock, the so-called pure-play time of the referee (Li-Hong 2005, 6; Simon 2007, pp. 223-224). This creates the possibility of obtaining at least one more point (a possible 3-point shot) than the team that executes its two one-point penalty shots is granted for the offense (that is, "good foul").

If foul play can bring a player or a player's team a positive result, then it is highly rated by community related to that team or player. This is similar in terms of the effectiveness future solutions that will not only be expected, but also desirable: if a player executes them in a way that the occurrence surprises competitors, the professionalism, and sophistication will impress the fans.

Fouls, fouling, and foul play may also enhance the course of the sports spectacle and encourage spectators to cheer more frequently. They more or less positively influence the structure and esthetics of sport spectacle. Due to the occurrence of fouls, the course of events is less schematic, less predictable, and aleatoric (Kosiewicz, 2010b). Also, the spectacle is more dramatic. There is authentic pain, suffering, blood from ahead injury, and limping. This dramatization is enhanced by a close-up visible on the stadium screen oron a spectators' television at home. This is also particularly important when professional athletic contests are treated as a form of business. The theatricalization of foul play as a creation of "game" within a game can also be an additional and desirable attraction of the competition; foul play might be used as sophisticated and spectacular trickery that dismays and hurts in its pragmatic-aesthetic construction both the referee and the opponent.

Foul play in sports has so many forms and will probably never lose its popular and sometimes spectacular character. Knowing that, everything should be done to protect players from bothersome health, interpersonal, and cultural disablements resulting from foul play.

The presented results regard the broadly defined social sciences of sport. They refer to sociology and social philosophy because the author considers the phenomena and importance of the foul in a social context. On the one hand, the paper is testimony to theoretical and sociological reflection on the role and importance of fouls, to the moral, pragmatic, and praxeological aspects of fouls, as well as to fouls, foul play, and gamesmanship in the society of people involved in sport. On the other hand, it is a philosophical reflection on fouling that is inherently connected with sports activities; it is a reflection that can be used in the continually developing philosophy of sport.

\section{REFERENCES}

Barsalou, L.W. (1999). Perceptual symbol system. The Behavioral and Brain Sciences, 22, 577-609.

Barsalou, L.W. (2008). Grounded cognition. Annual Review of Psychology, 59, 617-645.

Black, M. (1964). The gap between "Is" and "Should”. The Philosophical Review,73 (2), 165 -181.

Geach, P.T. (1977). Murder and sodomy. Philosophy,5 (197), 346- 348.

Dreyfus, H.L. (2004). What could be more intelligible than everyday intelligibility? Reinterpreting division I of Being and time in the light of division II. Bulletin of Science, Technology \& Society, 24 (3), 265-274.

FIFA (2007). Platini rules out video replays. Press releases from the 122nd Annual General Meeting of the International $\begin{array}{lllll}\text { Football Association } & \text { Board. } & \text { Retrieved } & \text { September } & 27,\end{array}$ http://www.fifa.com/worldfootball/news/newsid=606659.html

Fraleigh, W. (2007). Intentional rules violations - one more time. In W.J. Morgan, (Ed.), Ethics in sport (pp. 209218).Champaign, IL: Human Kinetics.

Frank, M.G. \& Gilovich, T. (1988). The dark side of self- and social perception: Black uniforms and aggression in professional sports. Journal of Personality and Social Psychology, 37, 74-85

Gallagher, S. (1992). Hermenutical Possibilities. In Hermenutic and Education (pp. 123-168). New York: State University New York Press.

Gallagher, S. (1993). The place of phronesis in postmodern hermenutics. Philosophy Today, 37, 298-305. 
Goffman, E. (1981). Człowiek w teatrze życia codziennego /The presentation of self in everyday life/. Warszawa: Państwowy Instytut Wydawniczy.

Hare, R.M. (1964). The Promising Game. Revue Internationale de Philosophie, 70, 398-412.

Hołówka, J. (1981). Relatywizm etyczny /Ethical relativism/. Warszawa: PWN.

Hume. D. (1947). Badania dotyczące rozumu ludzkiego /An enquiry concerning human understanding/. Kraków: PWN.

Hume, D. (1963). Traktat o naturze ludzkiej /A treatise of human nature/. Warszawa: PWN.

Hume, D. (1974). Związek konieczny /The necessary connection/. In: Jedynak, D. Hume (pp. 157-159). Warszawa: PW Wiedza Powszechna.

Jones, M.V., Paull, G.C. \& Erskine, J. (2002). The impact of a team's aggressive reputation on the decisions of association football referees. Journal of Sport Sciences, 20, 991-100.

Janus, T. (2010). Czy gra faul jest drogą do sukcesu w piłce nożnej? Analiza gry uczestników Mistrzostw Świata 2010 /Is foul play the way to success in football? Analysis of the play of participants of the 2010 World Cup/. Sport Wyczynowy, 3, 34-46.

Kosiewicz, J. (1989). W poszukiwaniu sensu i źródła wartości /In a quest for sense and source of values/. Człowiek i Światopogląd, 1, (276), 83-94.

Kosiewicz, J. (2010a). Aggression in sport. In Sport and Philosophy: From Ethics to Sport (pp. 284-295). Warsaw: BK Wydawnictwo i Księgarnie.

Kosiewicz, J. (2010b). The sporting spectacle from the point of view of aleatorism. In Sport and Philosophy: From Ethics to Sport (pp. 77-283).Warsaw: BK Wydawnictwo i Księgarnie.

Kosiewicz, J. (2010). Sport beyond moral good and evil. Physical Culture and Sport. Study and Research, vol. XLIX, 21-29.

Kotarbiński, T. (1982). Traktat o dobrej robocie/Praxiology. An introduction to the science of efficient action/. Wrocław: Zakład Narodowy im. Ossolińskich.

Lakoff, G. \& Johnson, M. (1980). Metaphors we live by. Chicago, London: The University of Chicago Press.

Leaman, O. (2001). Cheating and fair play in sport. In W.J. Morgan, K.V. Meier, A. J. Schneider (Eds.), Ethics in Sport (pp. 91-99). Champaign, IL: Human Kinetics.

Li-Hong (Leo) Hsu (2005). Revisiting fair play: cheating, the 'good foul' and sport rules. Academic Supplement of Fair Play! The Official Publication of the European Fair Play Movement, 4, 6-7.

Nevill, A.M., Belmer, N.J. \& Williams, M. (2002). The influence of crowd noise and experience upon refereeing decision in football. Psychology of Sport and Exercise, 3, 261-72.

Niedental, P.M., Barsalou, L.W., Wilkielman, P., Kraut-Gruber, S. \& Rick, F. Embodiment in attitudes, social perception, and emotion. Personality and Social Psychology Review, 9, 181-211.

Parry, J. (2002). Violence and aggression in contemporary sport. In J.M. McNamee and S.J. Parry (Eds.), Ethics and Sport (pp. 205-224). London and New York: Spon Press.

Philips, D.Z. (1965). The possibility of moral adviser. Analisis 25, (2), 37-41.

Reddiford, G. (2002). Cheating and self-deception in sport. In J.M. McNamee and S.J. Parry (Eds.), Ethics and Sport(pp. 225-239). London and New York: Spon Press.

Quadsnquebecke van, N. \& Giessner, S.R. (2010). Haw embodied cognition affects judgments: high-attribution bias in football foul calls. Journal of Sport \& Exercise Psychology, 32, 3-32.

Searle, J.R. (1978). Jak wywieść „,powinien” z ,jest” /How to derive “ought to” from “it is”/. Etyka, 16, 163-177.

Simon, R.L. (2007). The ethics of strategic fouling: a reply to Fraleigh. In W.J. Morgan (Eds.), Ethics in Sport (pp. 219227). Champaign, IL: Human Kinetics.

Tiryaki, M.S. (2005). Assessing whether black uniforms affect the decisions of Turkish soccer referees: Is the finding of Frank and Gilovich's study valid for Turkish culture. Perceptual and Motor Skills, 100, 51-57.

Szacki, J. (1981). Słowo wstępne [Introduction]. In E. Goffman, Człowiek w teatrze życia codziennego /The presentation of self in everyday life/. Warszawa: Państwowy Instytut Wydawniczy.

Warshaw, A. (2006, November 28). Blatter vows to block video evidence in the game. The Independent.

\section{AUTHOR'S ADDRESS: $\quad$ Jerzy Kosiewicz}

Department of Philosophy, Chair of the Social Sciences

Josef Pilsudski University of Physical Education in Warsaw

34 Marymoncka str., 00-968 Warsaw, Poland

Email: jerzy.kosiewicz@awf.edu.pl 